\title{
Correlating Bacharach Opacity in Fuel Oil Exhaust. Prediction of the Operating Parameters that Reduce It
}

\author{
M. Blanco' ', J. Coello', S. Maspoch ', A. Puigdomènech'1, X. Peralta², J.M. González² \\ and J. Torres ${ }^{2}$ \\ 1 Unitat de Química Analítica, Departament de Química, Universitat Autònoma de Barcelona, E-08193 Bellaterra - Spain \\ 2 Asfaltos Españoles SA, Refinería de Tarragona, PO Box 175, E- 43080 Tarragona - Spain \\ e-mail: j.coello@blues.uab.es
}

\begin{abstract}
Résumé - Corrélation de l'opacité Bacharach des gaz d'échappement. Prédiction des paramètres opérateurs qui la réduisent - Cette étude vise à déterminer les progrès à effectuer dans le contrôle de l'opacité Bacharach de la fumée dégagée par différents types d'équipements à fuel à travers une même cheminée. Afin de relier l'opacité Bacharach et les paramètres opérationnels de l'équipement de combustion, on a construit un modèle, sur la base de l'information recueillie lors d'un fonctionnement en routine pendant environ un an, sans expériences de laboratoire, ni altérations intentionnelles des paramètres.
\end{abstract}

Afin d'assurer la validité du modèle, on a appliqué différents outils chimiométriques aux données, recueillies sur une période suffisamment longue. Étant donné la grande complexité des données manipulées (paramètres d'équipement, propriétés du fuel-oil, conditions opérationnelles, etc.), le modèle a été construit à l'aide de différents outils de complexité croissante. Par conséquent, on a d'abord mené une analyse en composantes principales (PCA, Principal Component Analysis) sur les variables définissant les différents types de fuel-oil utilisés, afin de supprimer leur corrélation élevée. Les résultats de cette analyse ont été utilisés comme données dans les étapes suivantes.

À cause de la complexité élevée des paramètres impliqués, les méthodes de régression linéaire n'ont pas fonctionné, de sorte que, pour déterminer l'influence de ces paramètres sur l'opacité Bacharach, on a dû utiliser la méthode de régression non-linéaire ACE (Alternating Conditional Expectations).

Une fois le modèle construit, on a déterminé les paramètres gouvernant l'opacité, et le modèle a été validé expérimentalement par l'exploration des variables modifiables in situ (combinaison du coke Conradson et des asphaltènes dans le fuel-oil, viscosité de l'huile dans le brûleur et proportion d'oxygène dans le four). On a vérifié que les propriétés de l'échappement de la cheminée variaient avec ces paramètres; les prédictions du modèle ACE ont également été confirmées. La méthodologie proposée permet donc un contrôle effectif de la fumée dégagée par l'équipement.

Mots-clés : régression non-linéaire, alternance des expectatives conditionnelles (ACE), opacité Bacharach.

Abstract-Correlating Bacharach Opacity in Fuel Oil Exhaust. Prediction of the Operating Parameters that Reduce It - A study was conducted with a view to determining the steps to be taken in order to control the Bacharach opacity of smoke released by different types of engines powered by fuel oil through 
the same chimney. A statistical model was constructed to relate Bacharach opacity to the operational parameters of the burning equipment on the basis of information recorded during its routine functioning over a period of about one year, with no laboratory experiments nor intentional alteration of such parameters. Different chemometric tools were applied to the data recorded over a period long enough to ensure a good model. Owing to the high complexity of the data handled (equipment parameters, fuel oil properties, operating conditions, etc.), the model was constructed by using different tools that were tested in order of increasing complexity. Thus, a Principal Component Analysis (PCA) was initially conducted on the variables defining the different types of fuel oil used in order to suppress their high correlation. The scores obtained from this analysis were used as the fuel data in the subsequent steps.

Owing to the high complexity of the parameters involved, linear regression methods were not functional, so the non-linear regression method Alternating Conditional Expectations (ACE) had to be used instead to determine the influence of these parameters on Bacharach opacity.

After the model was constructed, the parameters that govern opacity were determined and the model was experimentally validated by exploring the variables that can be modified at plant level (viz. the combination of Conradson coke and asphaltenes in the fuel, the oil viscosity at burner and the proportion of oxygen in the furnace). Changes in these variables were found to alter the properties of the stack; also, the predictions of the ACE model were confirmed. Consequently, the proposed methodology allows the effective control of smoke released by the equipment.

Keywords: non-linear regression, Alternating Conditional Expectations (ACE), Bacharach opacity.

\section{INTRODUCTION}

Heavy fuel oils are widely used to power industrial furnaces and boilers; their burning produces gases and solid particles. The latter are variable in nature and result from burning of the fuel proper or from coalescence of particles in the smoke through increasing nucleation or aggregation [1]. According to size, they are designated soot (up to $1 \mu \mathrm{m}$ ) and cenospheres (1-100 $\mu \mathrm{m}$ in size).

The solid fraction in fuel oil exhaust contains not only carbonaceous particles but also a small amount of ash ( $\mathrm{V}, \mathrm{Na}, \mathrm{Ca}$ and $\mathrm{Fe}$ salts, silica, silicates, etc.) and the $\mathrm{SO}_{3} / \mathrm{H}_{2} \mathrm{SO}_{4} / \mathrm{SO}_{4}{ }^{2-}$ mixture [2].

One of the parameters typically used in controlling exhaust emissions is the blackening index. The Bacharach opacity test, established by ASTM D-2156, is a measure of blackening. The test involves passing a given volume of smoke through white filter paper that is visually compared in situ with a grey scale. The scale runs from white (0 Bacharach unit) to black ( 9 Bacharach units). The result is expressed to within 0.5 unit. There is no universal correlation between the Bacharach opacity of smoke and its mass content in solid particles as their size has a marked effect on the extent to which the filter paper used in the Bacharach test is blackened. Another influential factor is the smoke capturing temperature, which alters retention of $\mathrm{SO}_{3}$ aerosols and can result in slight burning of the filter paper. Spanish legislation [3] forbids emissions with a Bacharach opacity greater than 5 units from fuel oil burning sites.

Because of the complexity of the burning and particle formation processes, which depends on the nature of the fuel [4], the burning environment [5] and other design and operational parameters of the boiler or furnace [6], the steps to be taken with a view to correcting deviations from acceptable opacity values are not always obvious. No clear-cut correlation between Bacharach opacity and any fuel property seems to have been derived; the only two papers published on the subject lead to no firm conclusion in this respect $[7,8]$.

The aim of this work was to develop a chemometric approach to determining the potential relationship of operating variables to Bacharach opacity with a view to constructing a statistical model of assistance in taking the most appropriate steps to control it.

\section{BACKGROUND}

The non-linear, non-parametric multiple regression technique Alternating Conditional Expectations (ACE) estimates transformations for a response and a set of predictors [9]. These transformations may assist to the least-squares method because if simple transformations are suggested by ACE, they can be applied to the original variables, and the transformed variables can then be used as the regression variables in least-squares. The algorithm has so far been used to relate structure and activity (QSAR) [10, 11], in a comparative study of non-linear regression methods [12] and in environmental applications [13].

ACE methodology, based on Equation (1), may be used on both continuous or categorical data. It models a smoothed function of the response variable as a combination of smoothed functions of the independent variables:

$$
f(y)=\sum_{j=1}^{J} t_{j}\left(x_{j}\right)+e
$$


where $f(y)$ is the dependent variable function, $t_{j}$ that of the $j$-th independent variable and $e$ a term representing the error of fit. Smoothing here has the same meaning as in methods used to suppress oscillations (noise) superimposed on the value of the variable of interest.

ACE functions, which are called ACE transforms, are calculated in such a way as to minimise the sum of the squares of the model error:

$$
\sum_{i=1}^{0}\left(f\left(y_{i}\right)-\sum_{j=1}^{v} t_{j}\left(x_{j i}\right)\right)^{2} \Rightarrow \min
$$

These functions are not explicitly available in the algorithm, but rather as a series of $\left(f\left(y_{i}\right)-y_{i}\right)$ or $\left(t_{j}\left(x_{j}\right)-x_{j}\right)$ point pairs. For each transform, the number of point pairs available coincides with that of objects used for calibration. These points are usually plotted in a graph, from which the shape of the transform function is apparent. Transforms are estimated by using a smoothing procedure based on a local linear regression performed over an interval centred at $x_{j}$. The regression line thus obtained only allows one to estimate the function $f\left(y_{i}\right)$ because the line changes at the next $x_{j}$ point. The sequence of all possible regression lines leads to a non-linear function such as that of Figure 1. The window size used in the linear regression is very important. In ACE, the SPAN parameter is defined as the fraction of objects - not the range for the variable - that is considered in the local regression. The number of objects in the window must always be an odd number not smaller than 5 so that a point $x_{j}$ will be the central point. This SPAN value may be constant or variable. In the original algorithm [9], an automatic smoothing routine is defined, by which an interpolation between three preset SPAN values $(0.05,0.2$ and 0.5 ) is done to ensure the best possible local fitting. In the program used in this work, the SPAN parameter is automatically evaluated from 0.05 to 0.5 using a variable increment which is calculated using a local cross-validation. This technique may only be used if a large number of observations is available, otherwise a value of $0.2-0.4$ is advised.

A small SPAN value results in slight smoothing and, often, in considerable non-linearity, which, however, allows one to construct an overfitted model of little predictive capacity. On the other hand, a large SPAN value drastically smooths the functions and decreases non-linearity. At the limiting value, $\mathrm{SPAN}=1$, the transforms are straight lines. A paper has recently been published, concerning the optimal choice of the SPAN parameter for local polynomial estimation [14].

In addition to the transforms and the usual parameters employed to assess the goodness of fit and prediction, ACE provides a measure of the significance of the variables from the variance of the transforms. For ACE to be effective

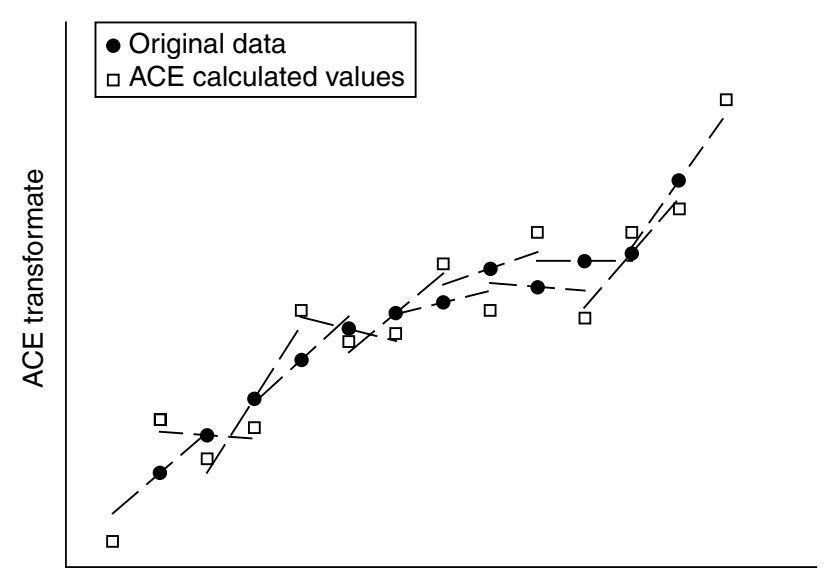

Variables

Figure 1

ACE smoothing.

in this respect, the following two conditions must be fulfilled:

- the number of objects used in the calibration must be much greater than that of independent variables;

- the independent variables must be as little correlated as possible.

\section{DESCRIPTION AND PRELIMINARY EXPLORATION OF THE DATA MATRIX}

Data were obtained from exhaust released through a chimney at the oil refinery of Asfaltos Españoles $S A$ in Tarragona (Spain). The chimney releases smoke from a thermal oil furnace and three steam boilers (the regular cogeneration boiler and two reserve ones). However, based on the amount of data available, only the usual working conditions were considered, namely: a B-106 thermal oil furnace (of $5 \mathrm{MW}$ thermal power) and the D-401 cogeneration boiler (of 11.5 MW thermal power). Both engines use the same fuel; however, owing to the lower yield of the B-106 furnace, and based on the Bacharach opacity of the chimney smoke, an additive can be added to the fuel burnt in the furnace to improve its performance.

Table 1 shows the 25 variables considered, which include properties of the fuel, adjustable operational parameters and exhaust composition. An overall 961 observations made from mid-1995 to late 1996 in the two cases considered (viz. furnace + boiler, with and without additive in the fuel oil burnt by the furnace), and 259 observations for the other situations - not considered in the study owing to the scarcity of data for each-were studied. 
TABLE 1

Variables with available values in the facility studied

\begin{tabular}{|c|c|}
\hline \multicolumn{2}{|l|}{ Fuel oil properties } \\
\hline Density at $15^{\circ} \mathrm{C}$ & Sulphur (w\%) \\
\hline Carbon Conradson residue (wt\%) & Asphaltenes content (wt\%) \\
\hline Viscosity at $50^{\circ} \mathrm{C}(\mathrm{cSt})$ & Viscosity at $82.2^{\circ} \mathrm{C}(\mathrm{cSt})$ \\
\hline Nickel (ppm) & Vanadium (ppm) \\
\hline Flash point & Oil viscosity at burner (cSt) \\
\hline \multicolumn{2}{|l|}{ Operational parameters } \\
\hline \multicolumn{2}{|l|}{ Fuel oil temperature $\left({ }^{\circ} \mathrm{C}\right)$} \\
\hline \multicolumn{2}{|c|}{ Addition of a combustion improver at furnace B-106 fuel oil (yes/no) } \\
\hline \multicolumn{2}{|c|}{ Steam production in boiler D-401 $(\mathrm{Tm} / \mathrm{h})$} \\
\hline \multicolumn{2}{|l|}{ Furnace B-106 } \\
\hline \multicolumn{2}{|l|}{ Number of burners (max 3 ) } \\
\hline \multicolumn{2}{|l|}{ Burner fuel oil pressure $\left(\mathrm{kg} / \mathrm{cm}^{2}\right)$} \\
\hline \multicolumn{2}{|c|}{ Draft at outlet in radiation section ( $\mathrm{mm}$ w.c.) } \\
\hline \multicolumn{2}{|l|}{ Flue gases composition } \\
\hline \multicolumn{2}{|l|}{ Stack } \\
\hline \multicolumn{2}{|l|}{ Bacharach opacity } \\
\hline \multicolumn{2}{|c|}{ Gases: $\mathrm{O}_{2}(\mathrm{vol} \%), \mathrm{SO}_{2}\left(\mathrm{mg} / \mathrm{Nm}^{3}\right), \mathrm{CO}(\mathrm{ppm}), \mathrm{NO}(\mathrm{ppm})$} \\
\hline \multicolumn{2}{|l|}{ Temperature $\left({ }^{\circ} \mathrm{C}\right)$} \\
\hline \multicolumn{2}{|l|}{ Furnace and boiler } \\
\hline \multicolumn{2}{|c|}{ Gases: $\mathrm{O}_{2}$ (vol\%), $\mathrm{CO}$ (ppm), NO (ppm) } \\
\hline
\end{tabular}

cSt: centistockes

mm w.c: water column millimeters

Processing this information posed a series of problems including:

- the large number of data to be handled in order to derive the significant information (i.e. to detect which variables influenced opacity and in what way);

- the two operating situations that can lead to a differential behaviour;

- determining the Bacharach opacity, which is a visual, scarcely sensitive measure ( 0.5 unit) that varies over a narrow range (90\% of data are typically within the range from 3 to 5 units).

\section{RESULTS AND DISCUSSION}

Parameter values were expressed in units of different magnitudes, so they were previously autoscaled [15]. This preliminary treatment ensured that the information considered would be the relative variation in the parameter values, whatever the magnitude of the units used to express them.

\subsection{PCA of the Fuel-Related Parameters}

A preliminary analysis revealed a high collinearity among the parameters defining the properties of the fuel (Table 2), which precluded assessing their significance as any regression model thus established would have been spurious. This affected not only correlated parameters but also all derived from them or involved in constructing the model, and led to false conclusions. For this reason, correlation among the variables used must be reduced in order to ensure obtainment of a robust model. No significant correlations were detected among the other variables.

Collinearity in the parameters was suppressed by using Principal Component Analysis (PCA) [16, 17] as implemented in the software Unscrambler 6.1 for Windows 95, from CAMO ASA (Trondheim, Norway). Autoscaled values for the following parameters were used: density at $15^{\circ} \mathrm{C}$ $\left(\mathrm{g} / \mathrm{cm}^{3}\right)$, sulphur $(\mathrm{wt} \%)$, viscosity at 50 and $82.2^{\circ} \mathrm{C}(\mathrm{cSt})$, Conradson coke (wt\%), flash point (W/M), asphaltenes $(\mathrm{wt} \%)$, nickel (ppm) and vanadium (ppm). The values recorded for all these variables over the studied period amounted to 10980 data (1220 observations $\times 9$ fuel-related parameters). The number of principal components (PCs) needed to describe the original data matrix from the variance

TABLE 2

Coefficients of correlation between the fuel-related parameters obtained by using the whole observation set (coefficients above $75 \%$ are boldfaced)

\begin{tabular}{l|c|c|c|c|c|c|c|c|c}
\hline & 1 & 2 & 3 & 4 & 5 & 6 & 7 & 8 & 9 \\
\hline 1 Density at $15^{\circ} \mathrm{C}$ & 1 & -0.41 & $\mathbf{0 . 8 8}$ & $\mathbf{0 . 8 8}$ & $\mathbf{0 . 8 5}$ & $\mathbf{0 . 8 6}$ & -0.61 & $\mathbf{0 . 8 0}$ & $\mathbf{0 . 7 5}$ \\
2 Sulphur & - & 1 & -0.69 & -0.70 & -0.70 & -0.71 & 0.54 & -0.52 & -0.33 \\
3 Conradson coke & - & - & 1 & $\mathbf{1 . 0 0}$ & $\mathbf{0 . 9 3}$ & $\mathbf{0 . 9 5}$ & $-\mathbf{0 . 8 1}$ & $\mathbf{0 . 8 9}$ & $\mathbf{0 . 7 8}$ \\
4 Asphaltenes & - & - & - & 1 & $\mathbf{0 . 9 3}$ & $\mathbf{0 . 9 5}$ & $-\mathbf{0 . 8 0}$ & $\mathbf{0 . 9 0}$ & $\mathbf{0 . 7 8}$ \\
5 Visc. 50 $50^{\circ} \mathrm{C}$ & - & - & - & - & 1 & $\mathbf{0 . 9 8}$ & -0.64 & $\mathbf{0 . 8 1}$ & 0.66 \\
6 Visc. $82.2^{\circ} \mathrm{C}$ & - & - & - & - & - & 1 & -0.66 & $\mathbf{0 . 8 3}$ & 0.68 \\
7 Flash point & - & - & - & - & - & - & 1 & $-\mathbf{0 . 7 9}$ & -0.73 \\
8 Nickel & - & - & - & - & - & - & - & 1 & $\mathbf{0 . 9 6}$ \\
9 Vanadium & - & - & - & - & - & - & - & - & 1 \\
\hline
\end{tabular}


accounted for by each was determined (Table 3). The first four PCs were found to account for $96.63 \%$ of the variance (i.e. to describe virtually the same amount of information as the nine original variables, in terms of new, uncorrelated variables). However, the first two components by themselves accounted for $86.7 \%$ of the initial variance $(77.7 \%$ with the first and $9 \%$ with the second). For this reason, only the PCA results provided by these two components were considered to interpret PCA graphics.

TABLE 3

Variance accounted for and cumulative variance as a function of the number of PCs for the fuel-related parameters

\begin{tabular}{c|c|c}
\hline PC & Explained variance & Cumulative variance \\
\hline 1 & 77.71 & 77.71 \\
2 & 9.03 & 86.74 \\
3 & 6.49 & 93.23 \\
4 & 3.40 & 96.63 \\
5 & 1.53 & 98.16 \\
\hline
\end{tabular}

\subsubsection{Loadings}

After the dimension of the data matrix was decided (number of PCs), the relationship between the calculated abstract parameters and the original variables was established from loadings graphs for the first two PCs-in subsequent calculations, however, the third and fourth PCs were also used for this purpose. The significance of a given parameter to each PC was dictated by its distance to the coordinate origin of the loadings graph. Figure 2 shows the loadings of the fuel-related variables for the first and second PCs. As can be seen, the first PC divides the variables in two groups: sulphur and vanadium contents in one hand, and the other seven variables in the other. Viscosities at $50^{\circ}$ and $82.2^{\circ} \mathrm{C}$ are highly correlated, as they appear almost with the same coordinates; this also happens for Conradson coke and asphaltenes contents. The second PC was dictated mainly by the sulphur and vanadium contents, as they present the highest score values for this PC.

\subsubsection{Scores}

Figure 3 shows the scores for the set of observations in the space bounded by the first two PCs. This graph reveals the presence of three distinct types of fuel over the studied period based on the coke + asphaltene content and flash point (i.e. the parameters essentially defining the first PC).

The scores for the first four PCs calculated by PCA were used instead of the nine initial fuel-related parameters in order to construct various statistical models.

\subsubsection{Linear Models}

Initial univariate regressions exposed no significant relationship between the different parameters and opacity, so various multiple linear regression methods, including regression of the whole parameter set, forward regression, backward regression and stepwise regression, were tested but, again, no satisfactory model could be obtained in this way.

In a subsequent step, the parameters were transformed in order to fit the behaviour of opacity to exponential, reciprocal and second-order models; however, the correlation level thus achieved never exceeded $20 \%$ in calibration.
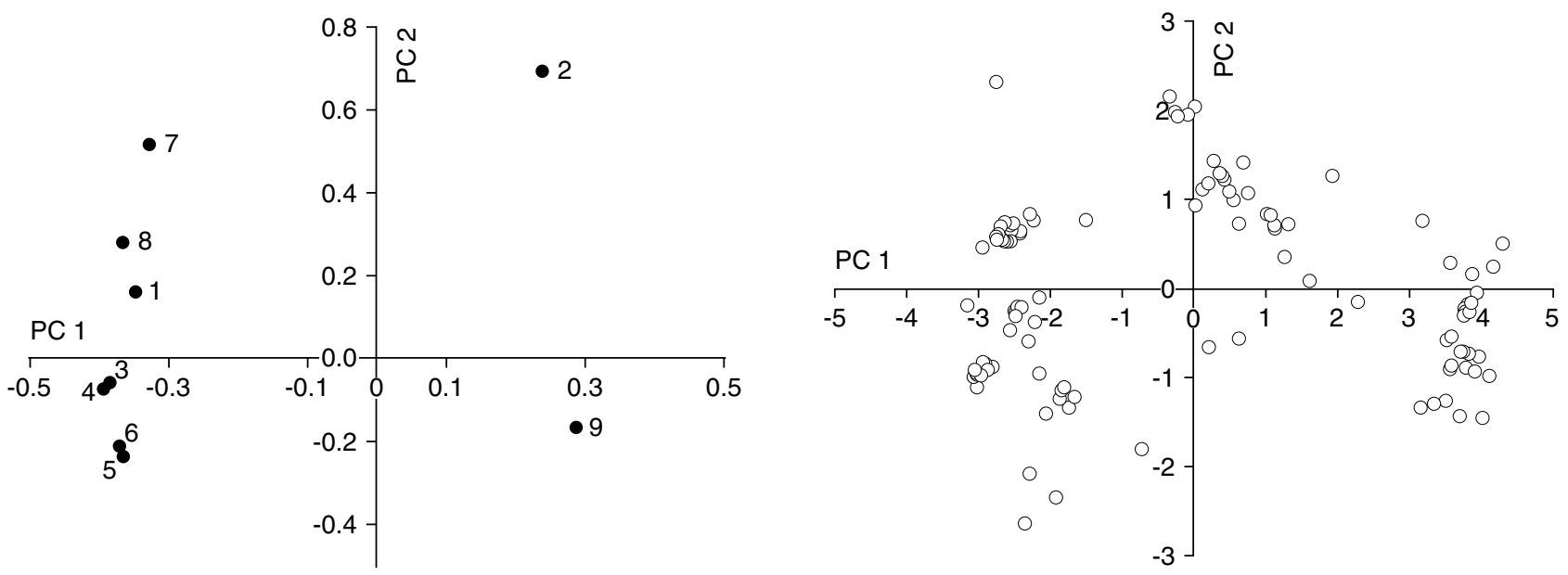

Figure 2

Loadings of the fuel-related parameters for the first and second PCs. (1) Density at $15^{\circ}$ C. (2) Sulphur. (3) Conradson coke. (4) Asphaltenes. (5) Viscosity at $50^{\circ} \mathrm{C}$. (6) Viscosity at $82.2^{\circ} \mathrm{C}$. (7) Flash point. (8) Nickel. (9) Vanadium.

Figure 3

Scores for the entire set of observations in the space bounded by the first and second PCs. The three types of fuel are framed. 


\subsection{Application of ACE}

Because no satisfactory model could be established with the above-described means, the model to relate opacity and the independent variables must be complex and non-linear. We chose ACE methodology to construct it. We examined two different operating conditions, namely:

- with the D-401 boiler on and the B-106 furnace using additive-containing fuel;

- the same configuration but with fuel containing no additive in the furnace.

Only under these conditions was the number of observations available large enough for effective application of ACE with a view to constructing robust models.

The ACE module, with autofitting of the SPAN value, implemented in the chemometric software package PARVUS 1.2 [18], was applied in order to model the behaviour of Bacharach opacity. Because ACE uses no implicit functions, but pairs of $\left(x_{i j}, y_{i}\right)$ points, it yields a graphical relationship between the independent variables and Bacharach opacity; also, it gives the percentage of fit for the calibration (viz. the calibration variance accounted for) and estimates the predictive power of the model (viz. the cross-validation variance accounted for) [19] by establishing 16 validation subsets. The cross-validation process involves splitting the data set into a series of subsets which are used to construct regression models from every subset, except one that is employed to predict the opacity and compare it with measured values. This process is performed with all the subsets established. In this way, an estimate of the predictive capacity of the model is obtained.

The parameters used to construct the model are shown in Table 4 . The data matrices consisted of 416 observations and 13 variables (5408 data) for the model including the fuel additive, and of 358 observations and 13 variables (4654 data) in the absence of additive. The fuel-related parameters used in both cases were the scores for the first four PCs instead of the original fuel variables.

\section{TABLE 4}

Independant variables used to construct the ACE model

\begin{tabular}{l|l}
\hline Stack temperature $\left({ }^{\circ} \mathrm{C}\right)$ & $\mathrm{O}_{2}$ in $\mathrm{B}-106(\mathrm{vol} \%)$ \\
score 1 fuel oil \\
$\mathrm{SO}_{2}$ in stack $\left(\mathrm{mg} / \mathrm{Nm}^{3}\right)$ & score 2 fuel oil \\
Oil viscosity at burner $(\mathrm{cSt})$ & score 3 fuel oil \\
Steam production by D-401 $(\mathrm{Tm} / \mathrm{h})$ & score 4 fuel oil \\
$\mathrm{O}_{2}$ in D-401 (vol\%) & \\
Number of burners at B-106 & \\
Burner fuel pressure in B-106 $\left(\mathrm{kg} / \mathrm{cm}^{2}\right)$ & \\
Draft at outlet in radiation section in B-106 & \\
$\quad(\mathrm{mm}$ w.c.) & \\
\hline
\end{tabular}

By way of an example, Table 5 shows the ACE results for the first combination (with additive); as can be seen, the more influential parameters (i.e. those spanning the widest ranges), in order of decreasing influence, were as follows: stack temperature, oil viscosity at burner, $\mathrm{SO}_{2}$ in stack, score 1 for the fuel, $\mathrm{O}_{2}$ in D-401 and steam production in D-401. By contrast, in the absence of additive in the fuel, the most influential parameters, in decreasing sequence, were as follows: $\mathrm{SO}_{2}$ in stack, $\mathrm{O}_{2}$ in $\mathrm{D}-401, \mathrm{O}_{2}$ in $\mathrm{B}-106$, score 1 for the fuel and oil viscosity at burner (Table 6).

TABLE 5

ACE results obtained with additive-containing fuel (the most significant variables are boldfaced)

\begin{tabular}{l|l|l}
\hline \multicolumn{2}{l}{ Explained variance } & $70.79 \%$ \\
\hline Calibration & $50.63 \%$ \\
Validation (16 groups) & Range & Variance \\
\hline Importance of transformates & $\mathbf{2 . 5 5 1 2}$ & $\mathbf{0 . 4 2 9 7}$ \\
\hline Variable & $\mathbf{1 . 5 1 0 8}$ & $\mathbf{0 . 1 4 4 5}$ \\
Stack temperature & $\mathbf{1 . 6 2 2 8}$ & $\mathbf{0 . 1 4 0 7}$ \\
SO, in stack & $\mathbf{1 . 3 2 4 9}$ & $\mathbf{0 . 1 3 4 2}$ \\
Oil viscosity at burner & $\mathbf{1 . 3 6 6 6}$ & $\mathbf{0 . 0 0 9 5}$ \\
Steam production by D-401 & 0.4851 & 0.0328 \\
O, in D-401 & 0.8241 & 0.0269 \\
Number of burners in B-106 & 0.4997 & 0.0067 \\
Burner fuel pressure B-106 & 0.6323 & 0.0206 \\
Draft at outlet in radiation section in B-106 & $\mathbf{1 . 3 9 2 4}$ & $\mathbf{0 . 1 0 4 1}$ \\
O in B-106 & 0.7331 & 0.0210 \\
Score 1 fuel oil & 0.6390 & 0.0190 \\
Score 2 fuel oil & 0.4022 & 0.0111 \\
Score 3 fuel oil & & \\
Score 4 fuel oil &
\end{tabular}

TABLE 6

ACE results obtained with fuel containing no additive (the most significant variables are boldfaced)

\begin{tabular}{l|l|l}
\hline Explained variance & \multicolumn{2}{|l}{$61.34 \%$} \\
Calibration & $36.92 \%$ \\
Validation (14 groups) & Range & Variance \\
\hline Importance of transformates & 0.6881 & 0.0133 \\
\hline Variable & $\mathbf{2 . 9 9 8 2}$ & $\mathbf{0 . 0 7 1 7}$ \\
Stack temperature & $\mathbf{1 . 2 6 2 6}$ & $\mathbf{0 . 0 7 7 8}$ \\
SO, in stack & 0.7618 & 0.0160 \\
Oil viscosity at burner & $\mathbf{2 . 8 6 8 6}$ & $\mathbf{0 . 1 4 9 9}$ \\
Steam production by D-401 & 0.4228 & 0.0039 \\
O, in D-401 & 0.4962 & 0.0237 \\
Number of burners in B-106 & 0.2754 & 0.0026 \\
Burner fuel pressure B-106 & $\mathbf{1 . 3 2 0 9}$ & $\mathbf{0 . 0 7 8 5}$ \\
Draft at outlet in radiation section in B-106 & $\mathbf{1 . 3 0 9 7}$ & $\mathbf{0 . 1 7 5 9}$ \\
O, in B-106 & 0.4830 & 0.0077 \\
Score 1 fuel oil & 0.6808 & 0.0139 \\
Score 2 fuel oil & 0.5442 & 0.0111 \\
Score 3 fuel oil & & \\
Score 4 fuel oil &
\end{tabular}


Figures $4 \mathrm{a}-4 \mathrm{~g}$ show the transforms provided by ACE, which expose the relationships between the different parameters and Bacharach opacity. An identical scale was used on the $y$-axis of all graphs to better expose the influence of each parameter. As can be seen, the relationships between the variables studied and Bacharach opacity are rather complex and different. The optimal transformations produced by the ACE algorithm are clearly not regular; also, the behaviour of some variables depends on the presence or absence of additives in the fuel, so it is not possible to find a model by least-squares fitting, and only a correlation of the original variables with the response may be proposed with the help of ACE transformations.

The sole prominent variables exhibiting the same trend in both types of situation are the oil viscosity at burner and Score 1 for the fuel. Other, less significant variables, exhibiting no clear-cut trend are the stack temperature, the $\mathrm{SO}_{2}$ content in stack and the oxygen content in smoke from both burning engines (furnace and boiler).

The oil viscosity at burner is a design parameter of the burning equipment and varies between recommended upper and lower limits. The multivariate correlation reveals the advisability of using a value near the lowest recommended by the manufacturer.

Bacharach opacity decreases with increase in Score 1 for the fuel and, as can be seen from the loadings graph (Fig. 2), a large value of this score is indicative of decreased contents in Conradson coke and asphaltenes. Figure 5 shows the variation of the Bacharach opacity in stack as a function of the combined Conradson coke + asphaltene content in the
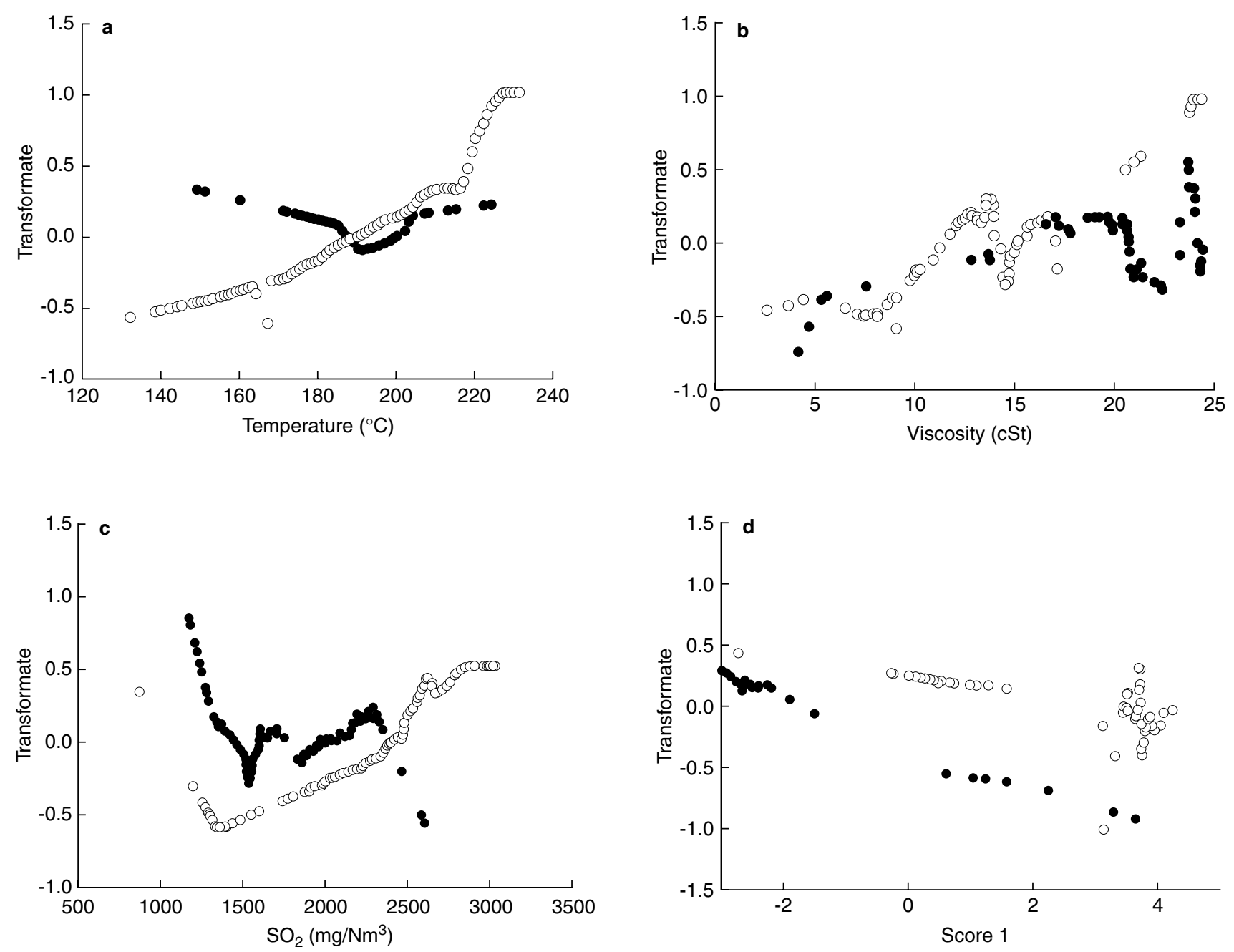

Figure 4

ACE transforms for the most significant parameters. (a) Stack temperature. (b) Oil viscosity at burner. (c) $\mathrm{SO}_{2}$ content in stack. (d) Score 1 for the fuel. With (o) and without $(\bullet)$ additive in the fuel. 

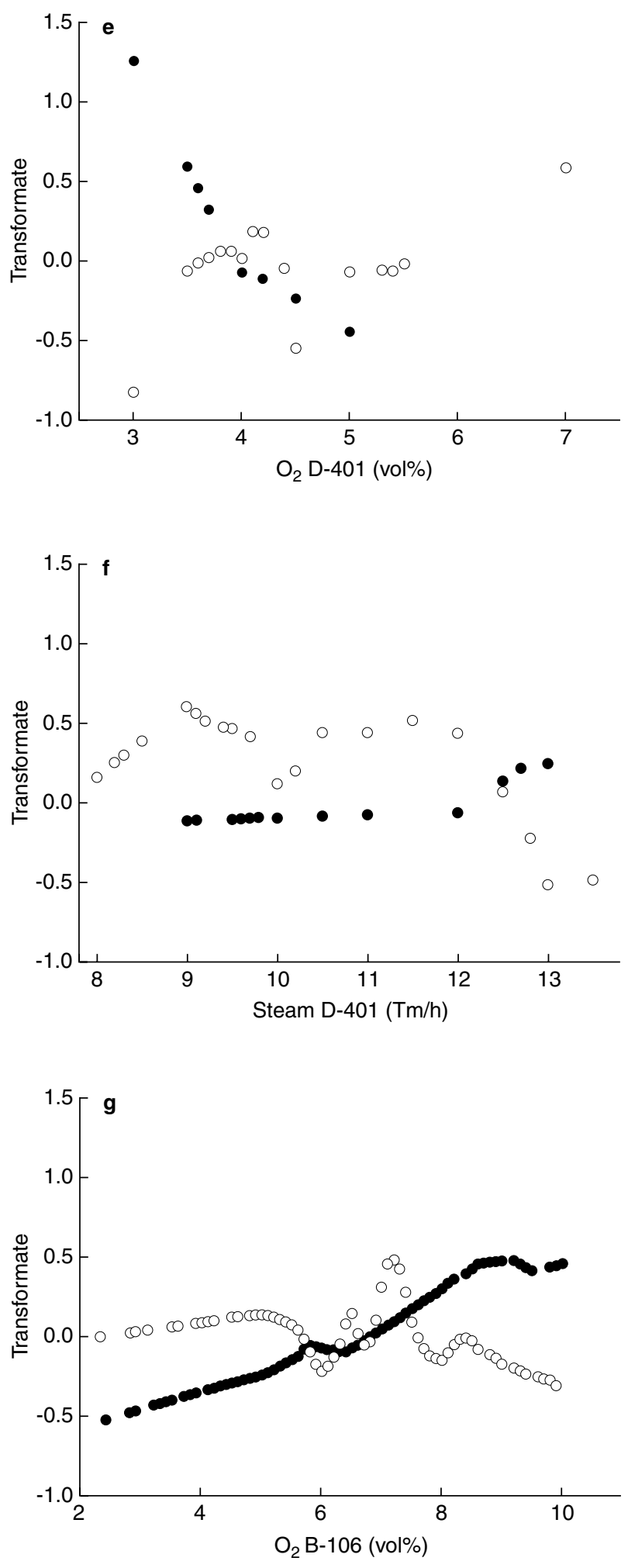

Figure 4

ACE transforms for the most significant parameters. (e) $\mathrm{O}_{2}$ content in D-401 boiler. (f) Steam production by D-401 boiler. (g) $\mathrm{O}_{2}$ content in B-106 furnace. With (o) and without $(\bullet)$ additive in the fuel.

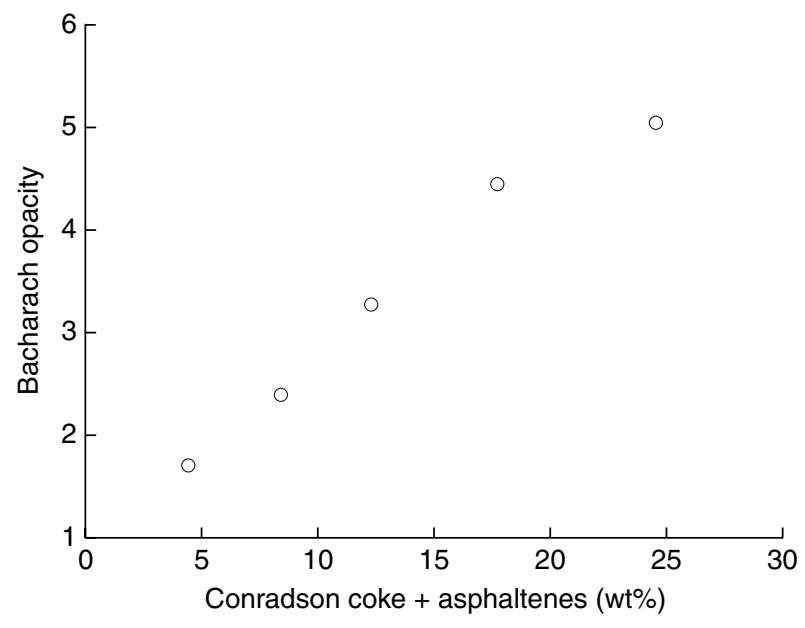

Figure 5

Relationship between Bacharach opacity and the combined Conradson coke + asphaltene content on constancy of all other parameters.

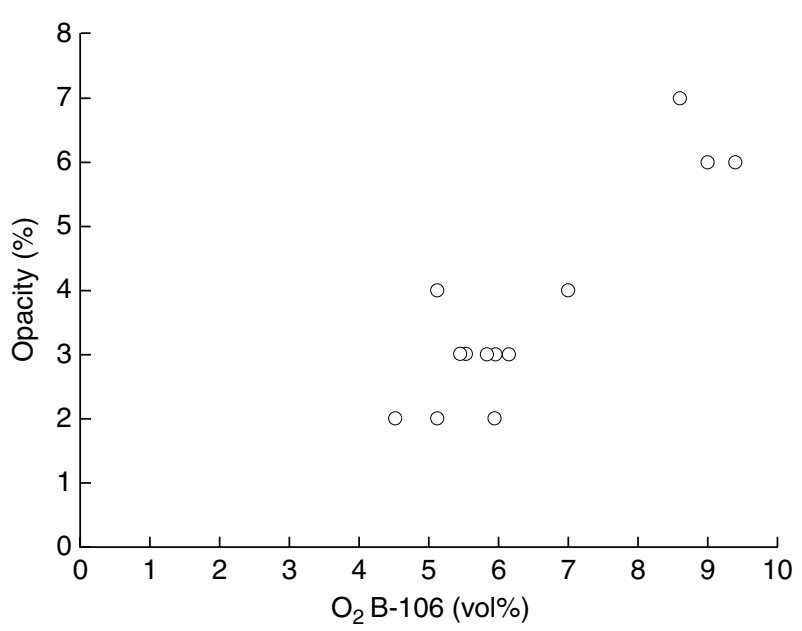

Figure 6

Variation of opacity at the output of B-106 furnace as a function of the $\mathrm{O}_{2}$ content.

fuel as determined in a field test where all other parameters were kept constant in the situation furnace + boiler with additive-containing fuel. As can be seen, fuel quality is highly influential on opacity.

The contradictory trends observed in the variables $\mathrm{SO}_{2}$, stack temperature and oxygen in the D-401 boiler in the two situations studied can be ascribed to:

- the fact that the $\mathrm{SO}_{2}$ content in stack varies over different ranges that hardly overlap in both situations;

- the scarcity of temperature data-all within a very narrow range-in one of the situations; 
- the narrow range of variation of the oxygen content in the D-401 boiler in both situations.

Consequently, the influence of these parameters on Bacharach opacity should be studied in greater depth in the future.

The actual contribution of the oxygen content in smoke from the B-106 furnace is illustrated in Figure 6, the $y$-axis in which represents the percent opacity, as measured with a continuous opacimeter, for furnace smoke; the results follow a trend consistent with that exposed by ACE.

\section{CONCLUSIONS}

The use of multivariate analysis techniques has proved a highly efficient tool with a view to modelling Bacharach opacity.

PCA efficiently solves the problems derived from correlation among the parameters that define the properties of the fuel used. The scores are employed as new, uncorrelated parameters in order to obtain reliable statistical models. In addition, PCA reveals the presence of three fuel classes depending on their combined coke and asphaltene contents.

ACE allows one to reliably determine which parameters influence Bacharach opacity and also, in a qualitative manner, in what way. The steps taken based on ACE transforms have proved effective at the petrochemical plant level.

The Bacharach opacity in stack increases with increasing Conradson coke and asphaltene contents in the fuel burnt by the different types of engines, and also with the oil viscosity at burner. The most immediate practical conclusion is that one should use values near the lower limit of the design range for the viscosity at burner tip, fix the limit of the Conradson coke + asphaltene content in the fuel supply and adjust the $\mathrm{O}_{2}$ content in the $\mathrm{B}-106$ furnace.

Bacharach opacity bears little quantitative relationship to the mass content of the emission, so applicable legislation should rather be based on particulate specifications.

\section{ACKNOWLEDGEMENTS}

The financial support from the Spanish government (DGICyT PB96-1180) is gratefully acknowledged.

\section{REFERENCES}

1 Kozinski, J.A. (1989) Characteristics of Soot Formation and Oxidation Regions in Turbulent-Diffusion Flames of Heavy Oils. Combust. Sci. and Tech., 65, 295-312.
2 Lammel, G. and Novakon, T. (1995) Water Nucleation Properties of Carbon Black and Diesel Soot Particles. Atmospheric Environment, 29, 813-823.

3 Decreto Ley 833/75 de 6 de Febrero (1975) BOE, April 22th, 1975, 96, 8611.

4 Audibert, F. and Bertrand, F. (1992) Modélisation de la combustion de fuels lourds prenant en compte la dispersion des asphaltènes. Oil \& Gas Science and Technology, 47, 269283.

5 Kozinski, J.A. (1994) PACs Formation and Interaction in Semipractical Flames of Liquid Fuels. Combustion and Flame, 96, 249-260.

6 Virto, D. (1993) La Naturaleza General de la Combustión de Combustibles Líquidos Atomizados. Jornada Tècnica "Combustió i control d'emissions", Institut Català de L’Energia, Barcelona, September.

7 Leary, J.A., Biemann, K., Lafleur, A.L., Kruzel, E.L., Prado, G.P., Longwell, J.P. and Peters, W.A. (1987) Chemical and Toxicological Characterization of Residential Oil Burner Emissions: I. Yields and Chemical Characterization of Extractables from Combustion of No. 2 Fuel Oil at Different Bacharach Smoke Numbers and Firing Cycles. Environmental Health Perspectives, 73, 223-234.

8 Lee, S.W., Preto, F. and Hayden, A.C.S. (1986) Determination of Fuel Aromatic Content and its Effect on Residential Oil Combustion. Preprints Papers Am. Chem. Soc., Div. Fuel Chem., 31, 3, 275-293.

9 Breiman, L. and Friedman, J.H. (1985) Estimating Optimal Transformations for Multiple Regression and Correlation. J. Am. Stat. Ass., 80, 580-619.

10 Frank, I.E. (1990) Regressione non lineare, in Proggetto COMMETT per la Chemiometria, Vol. 2, Gargnano.

11 Frank, I.E. and Lanteri, S. (1988) ACE: A Non-Linear Regression Model. Chemometrics Intell. Lab. Syst., 3, 301-313.

12 Cruciani, G., Baroni, M., Clementi, S., Costantino, G., Riganella, D. and Skagerberg, B. (1992) Predictive Ability of Regression Models. Part I. Standard Deviation of Prediction Errors (SDEP). J. Chemometrics, 6, 335-346.

13 Mallet, Y.L., Coomans, D.H. and de Vel, O.Y. (1995) Robust and Non-Parametric Methods in Multiple Regressions of Environmental Data, in Chemometrics in Environmental Chemistry, Einax, J. (ed.), Springer, Berlin.

14 Goldenshluger, A. and Nemirovski, A. (1997) On Spatially Adaptive Estimation of Nonparametric Regression. Mathematical Methods of Statistics, 6, 135-170.

15 Massart, D.L., Vandeginste, B.G.M., Deming, S.N., Michotte, Y. and Kaufman, L. (1988) Chap. 2 in Chemometrics: A Text Book, Elsevier, Amsterdam.

16 Jackson, J.E. (1991) A User's Guide to Principal Components, John Wiley \& Sons, New York.

17 Martens, H. and Nœs, T. (1991) Multivariate Calibration, Wiley, New York.

18 Forina, M., Leardi, R., Armanino, C. and Lanteri, S. (1990) PARVUS 1.2. An Extendable Open Package of Programs for Data Explorative Analysis, Classification and Correlation Analysis, Elsevier, Amsterdam.

19 Forina, M., Lanteri, S., Boggia, R. and Bertrán, E. (1993) Double Cross Full Validation. Quím. Anal., 12, 128-135.

Final manuscript received in April 2000 